\title{
O processo de autoria na perspectiva da Análise do Discurso ancorado na Base Nacional Curricular Comum brasileira
}

\section{The authorship process from the perspective of Discourse Analysis anchored in the Brazilian National Common Core Curriculum}

DOI: 10.46814/lajdv3n3-020

Recebimento dos originais: $01 / 05 / 2021$

Aceitação para publicação: 30/06/2021

\author{
Valéria André dos Santos \\ Mestre em Letras, PROFLETRAS/UNEMAT \\ Escola Estadual "Rui Barbosa" \\ Rua Arnaldo Mota, - Centro, Glória D'Oeste - MT, 78293-000 \\ E-mail: valeriasantos@unemat.br \\ Loiane Letícia dos Santos \\ Mestre em Psicologia e Saúde, FAMERP \\ Faculdade de Medicina de São José do Rio Preto - FAMERP
}

Av. Brigadeiro Faria Lima, - 5416 - Vila São Pedro, São José do Rio Preto - SP, 15.090-000

E-mail: loiane.psicologia@gmail.com

\section{Lorena Aline Santos Almeida}

Médica, Centro Universitário SÃO LUCAS

Pesquisadora Independente

E-mail: lorena_aline@gmail.com

Talessa Leonara Freire Bromate

Graduanda em Ciências Contábeis, FAPAN

R. São Luís, 2522 - Cidade Nova, Cáceres - MT, 78200-000

E-mail: talessa_leonarafb10@hotmail.com

\section{Leonila Santos Almeida Sasso}

Graduação em Enfermagem - FAIMI

Pesquisadora Independente

E-mail: leosaalm988@gmail.com

\section{Júlio César André}

Doutor em Ciências, Faculdade de Medicina de Ribeirão Preto - USP

Centro de Estudos e Desenvolvimento de Educação em Saúde da Faculdade de Medicina de São José do Rio Preto - CEDES/FAMERP

Av. Brigadeiro Faria Lima, - 5416 - Vila São Pedro, São José do Rio Preto - SP, 15.090-000

E-mail: julio.andre@famerp.br

\section{RESUMO}

Este artigo tem por objetivo apresentar uma prática de leitura e escrita na perspectiva discursiva, a partir de versões da literatura na reconstrução de histórias, tendo como foco a autoria. A base teórica que sustenta esta reflexão é a Análise do Discurso (AD), ancorada nos estudos de Michel Pêcheux, na França, e de Eni Puccinelli Orlandi, no Brasil, a Base Nacional Comum Curricular (BNCC) brasileira 


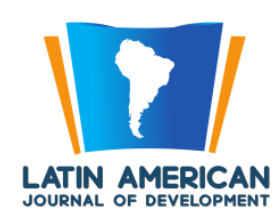

e o Documento de Referência Curricular de Mato Grosso (DRC-MT). A finalidade foi trabalhar discursivamente a obra literária, desenvolvendo competências e habilidades por meio de atividades que conduziram ao estabelecimento de relações de semelhanças e diferenças entre esses materiais, nas quais demos visibilidade aos efeitos de sentido produzidos, considerando os diferentes processos de constituição, formulação e circulação das diferentes materialidades significantes como produto final. As atividades foram realizadas entre 2019 e 2020, na Escola Estadual Rui Barbosa, distrito de Monte Castelo - Brasil, por meio de um projeto de leitura que se iniciou em 2012 e que vem se aperfeiçoando gradativamente, mas tem mostrado que vale a pena investir em práticas de sala de aula diferenciadas e contribuir de forma significativa para que todos que dele participarem promovam o crescimento intelectual e ampliem a perspectiva de futuro prevista na ótica educacional.

Palavras-chave: Leitura, autoria, escrita, Análise do Discurso, materialidade significante.

\begin{abstract}
This article aims to present a practice of reading and writing in the discursive perspective, from versions of literature in the reconstruction of stories, focusing on authorship. The theoretical basis that supports this reflection is Discourse Analysis (DA), anchored in the studies of Michel Pêcheux, in France, and Eni Puccinelli Orlandi, in Brazil, the Brazilian National Common Core Curriculum (BNCC) and the Curriculum Reference Document of Mato Grosso (CRD-MT). The purpose was to work on the literary work discursively, developing skills and abilities through activities that led to the establishment of relations of similarities and differences between these materials, in which we gave visibility to the effects of meaning produced, considering the different processes of constitution, formulation and circulation of different significant materiality as a final product. The activities were carried out between 2019 and 2020, at the State School "Rui Barbosa", Monte Castelo district - Brazil, through a reading project which started in 2012 and that has been gradually improving, but has shown that it is worth investing in different classroom practices and making a significant contribution so that everyone who participates in it promotes intellectual growth and expands the perspective of the future foreseen in the educational perspective.
\end{abstract}

Keywords: Reading, Authorship, Writing, Discourse Analysis, Significant materialities.

\title{
1 INTRODUÇÃO
}

A escola deve consolidar em sua proposta pedagógica a Base Nacional Comum Curricular (BNCC) (BRASIL, 2017) [1] a fim de oferecer e garantir uma educação de qualidade pautada em parâmetros legais que norteiem o seu fazer pedagógico. Implantando e seguindo essas habilidades e competências, a escola trilha seu caminho, respeitando todas as especificidades existentes no espaço escolar, e assim, acolhe todas as crianças, jovens e adultos com respeito e atenção adequada para que todos tenham igualdade de acesso e permanência na escola, formando cidadãos críticos capazes de agir na transformação da sociedade (ESCOLA ESTADUAL RUI BARBOSA, 2017) [2].

Precisamos, desde o início da vida escolar, enquanto professores, parafraseando Orlandi (2012, 2015) [3], problematizar as maneiras de ler, mostrando as condições de produção em que esta leitura está inserida, levar o sujeito falante ou leitor a refletir sobre questões que produz, o que vê e ouve nas diferentes manifestações da linguagem. “A leitura é uma prática que pressupõe a história e o trabalho 
de memória discursiva do sujeito no qual os sentidos são produzidos na relação com as condições de produção" (HASHIGUTI, 2009) [4]. O real da sala de aula é a heterogeneidade, a instabilidade, a polêmica, o litígio, a diferença; esse espaço precisa ser inundado por textos de diferentes materialidades significantes (FEDATTO \& MACHADO, 2007) [5], que circulam de diferentes maneiras, que possam remeter o aluno a um lugar povoado por várias vozes, em que os sentidos sejam plurais. Assim, haverá espaço para o discurso polêmico em que o objeto discursivo esteja em jogo, em situação de disputa e, dessa forma, ser desejado, escrito e falado pelos alunos e professores, aqui entendidos como sujeitos da linguagem (ORLANDI, 1988) [6].

Nesse sentido, a BNCC e a Constituição Brasileira, de onde a mesma emana, pontuam:

\begin{abstract}
“Artigo 206. O ensino será ministrado com base nos seguintes princípios: igualdade de condições para o acesso e a permanência na escola; liberdade de aprender, ensinar, pesquisar e divulgar o pensamento, a arte e o saber; pluralismo de ideias e de concepções pedagógicas, e coexistência de instituições públicas e privadas de ensino, gratuidade do ensino público em estabelecimentos oficiais; gestão democrática do ensino público na forma da lei; garantia de padrão de qualidade (BRASIL, 1988) [7]."

"Art. $26^{\circ}$. Os currículos do ensino fundamental e médio devem ter uma base nacional comum, a ser complementada, em cada sistema de ensino e estabelecimento escolar, por uma parte diversificada, exigida pelas características regionais e locais da sociedade, da cultura, da economia e da clientela". $\S 1^{\circ}$. Os currículos a que se refere o caput devem abranger, obrigatoriamente, o estudo da língua portuguesa e da matemática, o conhecimento do mundo físico e natural e da realidade social e política, especialmente do Brasil (BRASIL, 2017).”
\end{abstract}

O ensino da Língua Portuguesa mostra-se bastante enraizado em práticas ancoradas em programas de ensino, instrumentais de ensino (gramáticas, livros didáticos, dicionários, etc.) e os regulamentos que constituem uma formação discursiva que dá coesão a uma forma-sujeito e uma concepção do que significa sobre língua e saber a língua e essas práticas já saturadas na sala de aula se naturalizaram de tal forma que a relação dos alunos com a Língua Portuguesa não propicia ao aluno/sujeito se significar nela e, nesse sentido, sua relação com a leitura, se dá apenas na descrição e na contemplação da língua (DI RENZO, 2008)n[8]. Essas práticas estão enraizadas na Idade Média, em que apenas os cléricos eram autorizados a ler, falar e escrever em seus nomes, e o conjunto de todos os outros, cujos gestos incansavelmente repetidos de cópia, transcrição, extração, classificação, indexação, codificação constituíram uma leitura de apagamento do sujeito atrás da instituição que o empregava. Vemos essa questão em estreita relação com a noção desenvolvida por Pêcheux a respeito da divisão do trabalho social da leitura (PÊCHEUX, 1994,1995) [9,10].

De acordo com Sirian (2012) [11], o processo de naturalização do trabalho intelectual circunscreve, de um lado, o professor da universidade, do crítico, do pesquisador, no domínio do saber, sendo-lhe concedido "o direito de produzir leituras originais, logo, interpretações”, e, como tal, são autorizados e legitimados a elaborar o livro didático; do outro lado, no domínio do fazer, são inscritos 
os sujeitos da escolarização, os professores e alunos da escola, para quem é atribuída "a tarefa subalterna de preparar e de sustentar, pelos gestos anônimos de tratamento literal "dos documentos, as ditas interpretações..." (PÊCHEUX, 2006) [12]. O resultado dessa prática mantém o aluno alienado, numa posição sujeito apenas de recepção dos conteúdos, e tampouco participando como sujeitos protagonistas nas proposições da instituição. Razão pela qual, talvez, se apresente o discurso de preparar para o mercado de trabalho, pois lá também teria uma atuação passiva, apenas recebendo comandos (DALCICO, 2015) [13]. A escola produz o imaginário de lugar de formação de sujeitos do conhecimento, que ajam na transformação da sociedade. Para tanto, deveria oportunizar que o sujeito participasse ativamente de todas as ações promovidas no âmbito dos processos de ensino e das ações políticas da escola.

O Documento de Referência Curricular (DRC) de Mato Grosso (SECRETARIA DE ESTADO DE EDUCAÇÃO DE MATO GROSSO, 2010) [14] enfatiza a aprendizagem ativa, enquanto proposta para a ação pedagógica que advém da mudança no paradigma educacional em que a centralidade está no aprender fazendo e, sobretudo, na forma colaborativa desse fazer sob a mediação de um professor (JEREZ et al., 2010) [15]. Nessa perspectiva, o aprender nunca é passivo, está sempre em movimento (JEREZ, 2008) [16], é mobilizado e torna-se mobilizador de autoria dos sujeitos em processo de formação, pois está atrelado ao objetivo de tornar o estudante um sujeito competente para a resolução de problemas em diferentes campos da vida cotidiana. $\mathrm{O}$ aluno assume a posição de autor, em que controla os sentidos, em que amarra um imaginário de início, meio e fim subvertendo a ordem e tomando para si a responsabilidade do seu dizer. Fizemos essas considerações para sustentar o objetivo fundamental do projeto, que é trabalhar a leitura e a escrita na perspectiva discursiva para desenvolver a formação de leitores e autores, por meio da constituição de um arquivo de leitura, a partir da literatura, na (re)construção de histórias, a fim de dar a possibilidade de autoria a meus alunos, ou seja, realizar a "passagem", do oral para o escrito, ao assumir o seu dizer, colocando-se nesse processo. Como afirma Gallo (1990) [17], na "posição" de quem faz um texto (no momento em que os alunos estabelecem a relação do enredo com o desfecho) no espaço escolar.

Nesse sentido, o estudo objetivou o desenvolvimento de uma prática de leitura e escrita na perspectiva discursiva, a partir de versões da literatura para o teatro na reconstrução de histórias ou na forma de vídeos. O referencial teórico que sustentou esta reflexão é a Análise do Discurso (AD), ancorada nos estudos de Michel Pêcheux, na França, e de Eni Puccinelli Orlandi, no Brasil, a Base Nacional Comum Curricular (BNCC) brasileira e o DRC. 


\section{METODOLOGIA}

A sistemática consistiu, primeiramente, na realização da leitura gradativa de livros escolhidos pelos próprios alunos de forma receptiva e que rompessem com seu universo de expectativas, apoiandose nas marcas linguísticas, em seu conhecimento sobre o gênero e sobre a temática. Para tanto foi entregue dois ou mais exemplares de cada título disponível no acervo da biblioteca da escola, para que pudessem conversar a respeito e elabora perguntas entre os pares, finalizando assim com a escolha pessoal, onde os 2 ou mais alunos que escolhessem o mesmo título tornavam-se parceiro(s) de livro. A leitura foi feita então, de forma autônoma, acompanhada da compreensão, selecionando procedimentos e estratégias de leitura adequados a diferentes objetivos e levando em conta características dos gêneros e suportes (romances infanto-juvenis, contos populares, contos de terror, lendas brasileiras, indígenas e africanas, narrativas de aventuras, narrativas de enigma, mitos, crônicas, autobiografias, histórias em quadrinhos, mangás, poemas de forma livre e fixa como sonetos e cordéis, vídeo-poemas, poemas visuais, dentre outros) expressando avaliação sobre o texto lido e estabelecendo preferências por gêneros, temas, autores (ESCOLA ESTADUAL RUI BARBOSA, 2017).

Seguiu-se o conhecimento da materialidade, as condições de produção, o dito e não dito, valendo-se neste momento do preenchimento da ficha catalográfica. A etapa seguinte constituiu-se na ilustração do livro de acordo com as impressões produzidas e o que o título sugeria. Na sequência foram realizados encontros semanais no qual havia troca de perguntas, previamente elaboradas, ao(s) parceiro(s) de livro a respeito do mesmo. Uma nova etapa constituiu-se da contação do trecho lido oralmente, usando adequadamente ferramentas de apoio a apresentações orais (BRASIL, 2017), seguida da elaboração do resumo crítico, a partir das notas ou esquemas feitos e a elaboração do produto final, que se constituiu de um fragmento dos livros lidos, para ser inserido junto às apresentações do projeto de leitura que já acontece na escola.

A elaboração do texto teatral, a partir da adaptação de romances, contos, narrativas de enigma e aventura, novelas entre outros, explicitando a caracterização física e psicológica dos personagens, indicando as rubricas para caracterização do cenário, do espaço e do tempo, retextualizando o tratamento da temática (BRASIL, 2017), precedeu a produção de roteiros para elaboração de vídeos próprios das culturas juvenis tendo em vista os espectadores, o objetivo, as condições de produção, veículos e mídia de circulação, a partir do livro lido (BRASIL, 2017). Houve então a representação de cenas ou textos dramáticos, considerando, na caracterização dos personagens, os aspectos linguísticos e paralinguísticos das falas (timbre e tom de voz, pausas e hesitações, entonação e expressividade, variedades e registros linguísticos), os gestos e os deslocamentos no espaço cênico, o figurino e a maquiagem e elaborando as rubricas indicadas pelo autor por meio do cenário, da trilha sonora e da exploração dos modos de interpretação (ESCOLA ESTADUAL RUI BARBOSA, 2017). 
De suma importância, foi a etapa que consistiu na inferência da presença de valores sociais, culturais e humanos e de diferentes visões do mundo nos textos literários bem como a última etapa, que foi dedicada à avaliação "a fim de estabelecer o ponto de onde o sujeito da experiência partiu e que sofreu uma alteração após o processo" (GALLO, 1990) [17].

\section{RESULTADOS}

$\mathrm{Na}$ Escola Estadual "Rui Barbosa", como exemplo de parte das práticas já adotadas pela escola, que buscam atender às Orientações Curriculares do Estado de Mato Grosso, surgiu o projeto de leitura: "Ler, contar e recontar", iniciado no ano de 2012, a partir de uma inquietação: a de que os alunos apresentavam dificuldades de escrita e interpretação de texto em todas as disciplinas. A escola e mais precisamente, as professoras de Língua Portuguesa, conduzem este projeto desde então que tem como estímulo um passeio para aqueles que lerem e resenharem no mínimo um livro por bimestre. A metodologia utilizada consiste, primeiramente, na realização de leituras de romances diversos e, num segundo momento, na produção de uma resenha crítica, para a verificação do conteúdo lido, resultando em teatros ou vídeos. Esta forma de verificação efetiva da prática de leitura refletida na escrita tem nos mostrado que os modos de ler não estão de maneira alguma desvinculados das práticas de escrita.

Sendo assim, quanto mais o aluno lê, melhores condições têm para escrever. A leitura é de livre escolha e vinha afetando cada vez mais alunos e provocando a melhora na produção da escrita, na compreensão do mundo e na criticidade, sendo visivelmente percebida nos resumos dos livros produzidos, dando um efeito de completude no que se refere aos objetivos do projeto.

A escolha dos livros pelos próprios alunos apoiada nas marcas linguísticas, em seu conhecimento sobre o gênero e sobre a temática nos mostrou que os modos de ler não estão de maneira alguma desvinculados das práticas de escrita. Em nosso imaginário, quanto mais o aluno lê, melhores condições têm para escrever.

Foi possível a constituição de um arquivo de leitura, por meio de elaboração de resumos dos capítulos do livro, da produção de desenhos, de registros das discussões e de apontamentos, sendo possível a produção de um novo texto e permitindo, dessa forma, os gestos de autoria dos alunos e a transformação do aprendiz.

Foi possível analisar em textos narrativos ficcionais, as diferentes formas de composição próprias de cada gênero, apoiando-se nas marcas linguísticas, na temática dessas produções que representam um desafio em relação às suas possibilidades atuais e suas experiências anteriores de leitura.

Existe uma diferença entre os alunos que vivem na zona urbana, no distrito, aqueles que moram na zona rural, que são chamados de "caipiras", “sem cultura”, mas é possível observar que, entre os 
leitores da escola, metade é da zona rural e a outra metade é da zona urbana. Quanto à disciplina e ao interesse, os alunos da zona rural se destacam mais, buscam avidamente a escolaridade como forma de melhorar de vida, fazem faculdade e retornam como membros do quadro de professores da escola.

Assim, realizou-se um trabalho segundo as bases teóricas da $\mathrm{AD}$, levando em consideração que o sujeito-leitor tem suas especificidades, sua história de leitura, sua particularidade.

\section{DISCUSSÃO}

Nesta ótica a Escola Estadual "Rui Barbosa", pode ser observada como ponto de partida, a saber que: deve orientar sua ação pedagógica administrativa por meio deste Projeto, documento de construção coletiva, politicamente comprometido com as Diretrizes Curriculares Nacionais e as Orientações Curriculares para a Educação Básica de Mato Grosso (SECRETARIA DE ESTADO DE EDUCAÇÃO DE MATO GROSSO, 2010), em que se lê: “tem como compromisso garantir educação com qualidade social, proporcionando ao estudante o desenvolvimento de capacidades e a construção de conhecimentos para a formação de valores humanos na conquista da cidadania plena".

Após iniciado as leituras na perspectiva discursiva, compreendeu-se que ao analisar as páginas de um livro, o projeto: "Ler, contar e recontar", se reporta às ideias principais do texto ou à intenção do autor, por meio de perguntas de conteúdo relacionadas à coesão e coerência que deixam de lado questões que nos remetem a outro percurso de leitura, que desconfia de tudo que possa ser afirmado como óbvio como, por exemplo: “o que este texto não discute?” (LAGAZZI-RODRIGUES, 2011) [18] e que poderiam ser mais pertinentes e interessantes à compreensão e ao interesse dos leitores. Para a $\mathrm{AD}$, a leitura é compreendida enquanto produção de sentidos, pois, o sujeito-leitor, constituído por esses efeitos, representa a conjunção de duas historicidades: a história de suas (do leitor) leituras e a história de leituras do texto [...] que atuam dinamicamente na constituição de uma 'sua' leitura específica, em um momento dado (BOLOGNINI \& PFEIFER, 2009) [20].

Existe, nesse sentido, uma necessidade de: “Oferecer aos alunos elementos para que discutam as condições de produção dos diversos discursos para que as questionem, de modo que os outros sentidos também históricos sejam evidenciados e eles se desloquem e ocupem outra posição sujeito. Para a AD, o deslocamento está na possibilidade de produzir efeitos de sentido diferentes daqueles estabilizados em seu grupo social (BOLOGNINI \& PFEIFER, 2009). Dessa forma, por meio de um trabalho com e na diferença, para promover deslocamentos nesse modo de ler, objetivamos dar condições para que os alunos possam (se) dizer e se apropriar de diferentes materialidades para ampliar seu repertório de leitura e para produzir o vínculo professor-aluno / conhecimento: "No trabalho simbólico estruturado na incompletude e na contradição, imagens, palavras, gestos, sons, música 
compõem possibilidades de deriva e nos deixam ver a diferença em sua potencialidade de trazer à tona o político no social" (LAGAZZI, 2012) [21].

Segundo a $\mathrm{AD}$, a leitura preocupa-se com o sentido, não o literal, exclusividade do professor ou do autor. Por essa perspectiva, não se pode silenciar outras possibilidades de interpretação e, dessa forma, o professor pode modificar as condições de produção da leitura do aluno: de um lado, propiciando-lhe que construa sua história de leituras; de outro, estabelecendo, quando necessário, as relações intertextuais, resgatando a história de sentidos do texto (ORLANDI, 2015). A análise do Discurso, pode ser entendida como uma "teoria da interpretação" que busca, desde sua origem, compreender "como um texto significa", refletindo sobre o "como" é constituído com suas condições de produção e como são produzidos os efeitos de sentido, se tornando fundamental neste processo de transformação. Nessa teoria, "considera-se que a leitura é produzida e se procura determinar o processo e as condições de sua produção" (ORLANDI, 1993) [22], condições estas que precisam considerar os sujeitos (autor e leitor), a ideologia, os diferentes tipos de discurso, a distinção entre leitura parafrástica e a polissêmica, a fim de instalar novos sentidos na sala de aula, deslocando o aluno do lugar de mero receptor de conteúdos e sentidos já legitimados e sinalizando para a possibilidade de expressão, questionamentos e dúvidas.

Antes de conhecer a teoria, acreditava que a leitura devia ser sempre da linguagem verbal; após estudos na Análise de Discurso, descobriu-se também a importância da linguagem visual e sonora, com o objetivo de explorar os detalhes de uma cena e verificar de que forma os objetos simbólicos produzem efeitos de sentido (ORLANDI, 2015). E foi assim que se chegou a um resultado: numa sucessão de leituras do livro, dos filmes e desenhos e das discussões a respeito dos efeitos de sentido de cada um e de todos entre si que foi possível à construção do produto final. Uma nova versão para a história de Peter Pan, trazendo para os dias atuais essa história, apresentada numa noite festiva para a comunidade escolar, mostrando os efeitos de autoria: “O autor é, pois, o sujeito que, tendo o domínio de certos mecanismos discursivos, representa, pela linguagem, esse papel, na ordem social em que está inserido" (ORLANDI, 2012).

Para tanto, entendemos ser necessário formar um arquivo de leitura, para que, nessa atividade, "os alunos comecem a se colocar na condição de autoria assumindo diante da instituição-escola e fora dela, um papel social na relação com a linguagem" (ORLANDI, 2012). Para ensinar leitura, é preciso dar condições para que o leitor trabalhe com o que ele não sabe. A leitura pode ser pensada justamente como a construção dessa relação entre o discurso e o texto e é aí que o professor pode dar elementos para o leitor aprendiz (ORLANDI, 2012) [23]. O conjunto de leituras feitas pelos alunos configura, em parte, a compreensibilidade de cada leitor específico e é importante refletir sobre a possibilidade de a leitura ser trabalhada, de que a leitura faça parte do processo de instauração dos sentidos e de que 
estamos expostos à ela o tempo todo e nosso aluno também, mas o que nos diferencia uns dos outros é a singularidade e a maneira como cada sujeito se posiciona diante de um objeto a ser lido e interpretado, registrado por meio da escrita ou de outros suportes de circulação. Ou seja, a leitura é atravessada pela memória discursiva das leituras anteriores feitas pelo sujeito ou por outros leitores, pois elas produzem efeitos resultantes do cruzamento de outras. Sendo assim, o que fica para nós é que é a forma como o professor oportuniza as condições de produção da leitura no contexto escolar que vai possibilitar aos alunos ler de maneira que novos sentidos serão produzidos. A constituição do arquivo de leitura contou com a elaboração do texto de forma reflexiva no qual puderam exercer uma crítica reveladora da relatividade do sentido do texto e da institucionalização deste por outro, construindo uma determinada direção, deixando de lado muitas direções possíveis que sua história poderia ter tomado (GALLO, 1990). Houve espaço para a escrita, a reescrita, a revisão, os ensaios para a encenação, a confecção de cartazes e convites impresso e/ou manuscrito, conforme as condições solicitadas. Cada grupo, a partir do eixo temático de sua preferência, anunciada no primeiro encontro com a turma, na roda de conversa (magia, amor, comédia e aventura), fez o seu texto, levando em conta a autoria: “o sujeito só se faz autor se o que ele produz for interpretável" (ORLANDI, 2009) [24]. É assim que compreendemos que estamos criando as possibilidades para os deslizamentos de sentido, de forma que os alunos ressignifiquem o que já foi dito, constituindo-se autores deste processo. Os alunos conseguiram fazer esta "passagem", a partir do momento em que se constituíram autores das peça de teatro e dos vídeos, produzidos, revisados e apresentados por eles, a partir das leituras.

Ao se criar um espaço no qual acontecesse a repetição histórica a partir do que os alunos já sabem para a elaboração de outras formas de conhecimento efetivo em suas condições, a partir de recortes de certas zonas do interdiscurso, que permitam reconhecer, como afirma Hashiguti (2009), “o discurso lúdico no qual os interlocutores estão expostos ao referente havendo circulação de sentidos, ou seja, a polissemia aberta". É nessa polissemia que jogam as posições-sujeito professor e aluno. O equívoco é a única certeza. A melhor certeza. Muitos sentidos podem se fazer possíveis nessa relação. São as materializações da constituição da história (FEDATTO \& SILVA, 2011) [25]. O fazer do professor precisa ser nutrido por uma teoria; essa relação se constrói à medida que o professor lê, é interpelado, olha para a sua prática, avalia, estabelece relações, troca experiências com os colegas e se reconhece como passível de transformações: O professor pode modificar as condições de produção da leitura do aluno: de um lado, propiciando-lhe que construa sua história de leituras; de outro, estabelecendo, quando necessário, as relações intertextuais, resgatando a história de sentidos do texto (ORLANDI, 2015). 


\section{CONCLUSÕES}

Ao realizar-se um trabalho segundo as bases teóricas da $\mathrm{AD}$, levando em consideração que o sujeito-leitor tem suas especificidades, sua história de leitura, sua particularidade possibilitou-se criar um espaço no qual acontecesse a repetição histórica a partir do que os alunos já sabem para a elaboração de outras formas de conhecimento efetivo em suas condições, a partir de recortes de certas zonas do interdiscurso, que permitam reconhecer.

A BNCC, defende propostas pedagógicas atentas à progressão e ao desenvolvimento pleno do aluno como ser integrante e protagonista de práticas sociais nos vários campos de atuação e a DRC a aprendizagem ativa. Com estas três vertentes pedagógicas, está sendo possível realizar este projeto que já é piloto no município e serve de modelo a outras instituições.

Como resultados expressivos, foi possível verificar que o número de alunos que buscaram o ensino superior ao término do ensino médio, depois da implantação do projeto foi significativo, isso se deve à descoberta de novas perspectivas de melhorias que a leitura desperta. Outro fato que merece menção, é o de que vários de nossos alunos, conseguiram nota significativa na redação do Exame Nacional do Ensino Médio (ENEM) brasileiro, como resultado provável da leitura que aumentou seu repertório vocabular, sua criticidade e visão de mundo.

Uma outra conquista é que alguns alunos fazem da leitura um hábito mesmo sem estar participando das premiações, demonstrando que o objetivo do projeto foi atingido: criar um público leitor. Tivemos a grata satisfação de ter como leitores alunos que vivem em situações de risco e que a leitura auxiliou a ter novas perspectivas, já que o projeto também oportuniza aos alunos ter um momento de lazer e cultura além dos livros e do espaço em que vivem. Nas duas edições anteriores, os alunos que ganharam em primeiro, segundo e terceiro lugar, tiveram direito a uma viagem cultural para São Paulo, capital cultural brasileira, com transporte aéreo (uma quase irrealidade material para indivíduos com estas origens sociais e econômicas) para conhecer os principais pontos turísticos, patrocinada por uma pessoa anônima que já financia as medalhas por acreditar ser imprescindível incentivar um projeto com esta importância para a comunidade escolar e para a sociedade.

Vale lembrar que não é possível inventar uma receita. Nosso projeto é único e mesmo que alguém queira copiá-lo, ou seja, usar a mesma metodologia, os resultados serão outros, pois os sujeitos não serão os mesmos, as condições de produção serão outras, o tempo será outro, o professor será outro, as atividades poderão ser outras etc. São as condições de produção em que as atividades foram pensadas e a turma escolhida que irão proporcionar o diferente em qualquer proposta. É a maneira como se oportuniza as condições de produção da leitura, num processo de ressignificação da divisão social desse trabalho, que se vai despertar o interesse dos alunos, visto que os sentidos não são únicos, nem devem ser administrados na sala de aula. É dessa forma que compreendemos a constituição de 
autoria dos alunos em relação à produção da leitura e da escrita, de maneira que o seus dizeres possam ser legitimados (SANTOS et al., 2020).

O desenvolvimento do projeto aqui descrito tem mostrado que vale a pena investir em práticas de sala de aula diferenciadas considerando a evolução significativa do mesmo. Nessa perspectiva, o papel dos professores na aprendizagem é de mediador, estimulador de ideias e de conexões para a promoção de uma aprendizagem ativa. Conhecer os estudantes em seus interesses, culturas, estilos de aprendizagens favorece uma relação entre professor-estudante de segurança e de confiança na capacidade de aprendizagem, com o intuito de integrá-los em suas diferenças. Assim, acreditamos que a continuidade deste projeto deva contribuir de forma significativa para que todos que dele participarem promovam o crescimento intelectual e ampliem a perspectiva de futuro na ótica educacional. 


\section{REFERÊECIAS}

BRASIL. Base Nacional Comum Curricular. Brasília: Ministério da Educação, 2017. Disponível em: http://basenacionalcomum.mec.gov.br/images/BNCC_publicacao.pdf. Acesso em: 9 abr. 2021.

ESCOLA ESTADUAL RUI BARBOSA. Ensino Fundamental, Médio e Profissional. Projeto Político Pedagógico (PPP). Novas Laranjeiras: Escola Estadual Rui Barbosa, 2017. Disponível em: http://www.nljruibarbosa.seed.pr.gov.br/redeescola/escolas/31/1714/627/arquivos/File/PPPRUIBAR BOSA2018_doc.pdf. Acesso em: 9 abr. 2021.

ORLANDI, E. P. Discurso e Leitura. 9. ed. São Paulo: Cortez, 2012.

ORLANDI, E. P. Análise de Discurso. Princípios e Procedimentos. 9. ed. Campinas: Pontes, 2015.

HASHIGUTI, S. T. Nas teias da leitura. In: BOLOGNINI, C. Z. (org.). Discurso e ensino: prática de linguagem na escola. Campinas: Mercado de Letras, 2009. p.19-27.

FEDATTO, C. P.; MACHADO, C. P. (2007). O muro, o pátio e o coral ou sentidos no/do professor. In: BOLOGNINI, C. Z. (org.). Discurso e ensino: o cinema na escola. Campinas: Mercado de Letras, 2007. p. 9-15.

ORLANDI, E. P. "Nem escritor, nem sujeito, apenas autor". In: . Discurso e leitura. São Paulo: Cortez; Campinas: Editora da Unicamp, 1988. p. 75-84.

BRASIL. [Constituição (1988)]. Constituição da República Federativa do Brasil: texto constitucional promulgado em 5 de outubro de 1988, com as alterações determinadas pelas Emendas Constitucionais de Revisão nos 1 a 6/94, pelas Emendas Constitucionais nos 1/92 a 91/2016 e pelo Decreto Legislativo no 186/2008. - Brasília: Senado Federal, Coordenação de Edições Técnicas, 2016. E-book. Disponível em: https://www2.senado.leg.br/bdsf/bitstream/handle/id/518231/CF88_Livro_EC91_2016.pdf. Acesso em: 9 abr. 2021.

DI RENZO, A. M. Escola e a formulação de políticas linguísticas. Revista de Letras da Universidade Católica de Brasília, Brasília, v. 1, n. 2, p. 5-15, jan. 2008. Disponível em: http://www.unemat.br/caceres/letras/docs/docente/ana_di_renzo_escola_formulacao_politicas.pdf. Acesso em: 9 abr. 2021.

PÊCHEUX, M. Ler o arquivo hoje. In: ORLANDI, E. P. (org.). Gestos de Leitura: da História no Discurso. Campinas: Editora da Unicamp, 1994. p. 49-59.

PÊCHEUX, M. Semântica e Discurso: uma crítica à afirmação do óbvio, 2. ed. Campinas: Edunicamp, Unicamp, 1995.

SARIAN, M. C. A injunção ao novo e a repetição do velho: um olhar discursivo ao Programa um Computador por Aluno (PROUCA). 2012. 274 f. Tese (Doutorado em Linguística) - Universidade Estadual de Campinas, Instituto de Estudos da Linguagem, Campinas, 2012. Disponível em: http://www.repositorio.unicamp.br/handle/REPOSIP/27053. Acesso em: 9 abr. 2021.

PÊCHEUX, M. O Discurso. Estrutura ou Acontecimento. 4. ed. Campinas: Pontes, 2006. 
DALCICO, E. C. Novos gestos de interpretação: o desafio de "Ensinar" a ler. 2015. 122 f. Dissertação (Mestrado Profissional em Letras) - Universidade do Estado de Mato Grosso, Cáceres, 2015. Disponível

em: http://portal.unemat.br/media/files/profLetrasCACERES/ELIANE\%20DALCICO.pdf. Acesso em: 9 abr. 2021.

SECRETARIA DE ESTADO DE EDUCAÇÃO DE MATO GROSSO. Diretrizes curriculares: concepções para a educação básica. Cuiabá: SEDUC/MT, 2010.

JEREZ, F. O., CORONADO, G., VALENZUELA, G. A Development Model of Social responsibility Competencies for Sustainable Development in the School of Economics and Business of the University of Chile. In: GONÇALVES,F.; PEREIRA, W. L.; MIRANDA, U. Constributions to the Decade of Eduaction for Sustainable Development. Switzerland: Bern, 2010. p. 899-911.

JEREZ, O. Comprendiendo el Enfoque de Competencias. Santiago: Corporación Sofofa, 2008.

GALLO, S. L. Ensino da linguagem escrita x o ensino do discurso escrito. 1990. 148 f. Dissertação (Mestrado em linguistica) - Universidade Estadual de Campinas, Campinas, 1990. Disponível em: http://repositorio.unicamp.br/jspui/bitstream/REPOSIP/270686/1/Gallo_SolangeLeda_M.pdf. Acesso em: 9 abr. 2021.

LAGAZZI-RODRIGUES, S. M. Análise de Discurso: a materialidade significante na história. In: DI RENZO, A.; MOTTA, A. L. R.; OLIVEIRA, T. P. (org.). Linguagem, História e Memória: discursos em movimento. Campinas: Pontes, 2011. p. 275-290.

BOLOGNINI, C. Z.; PFEIFER, E C. L. S. (orgs.). Práticas de Linguagem na Escola. Campinas: Mercado das Letras, 2009.

LAGAZZI, S. O discurso em diferentes territórios: o vermelho entre todas as cores. In: O. MALUFSOUZA, O. et al (orgs). Discurso, Sujeito e Memória. Campinas: Pontes, 2012. p. 133-146.

ORLANDI, E. Nem escritor, nem sujeito: apenas autor. In.: Cortez; Campinas, SP: Editora da UNICAMP, 1993. p. 75-82. . Discurso e leitura. São Paulo:

ORLANDI, E. P. Discurso e Texto - Formulação e Circulação dos Sentidos. 3. ed. Campinas: Pontes, 2012.

ORLANDI, E. P. A linguagem e seu funcionamento: as formas do discurso. 5. ed. Campinas: Pontes, 2009.

FEDATTO, C. P.; SILVA, R. Terra do Nunca e verdade - A história dos sentidos. In: Bolognini, C. Z. (org.). Discurso e ensino: A leitura no cinema. Campinas: Mercado de Letras, 2011, p. 31-38.

SANTOS, V. A. et al. Readings and Versions of Peter Pan in the Discursive Perspective. Journal of Studies in Education, Las Vegas, v. 10. n. 2, p. 56-67, may. 2020. DOI: https://doi.org/10.5296/jse.v10i2.16723 